\title{
Biodiversity conservation in a wild therapeutic garden; the case of Takiwasi center botanical reserve in the peruvian high-amazon
}

\begin{abstract}
Born as a center for the treatment of addiction and mental health and for the research on traditional Amazonian medicine, the Takiwasi Center, located in the Peruvian high-Amazon, over more than 25 years of existence has developed a series of parallel activities focused on the conservation of the environment and the recovery and promotion of Amazonian medicinal flora and of the indigenous knowledge related to it, within the general frame of "planetary health".

In this context, an on-site Botanical Garden has been created with a linked plant nursery that produces timber and medicinal species that are later transplanted into the Botanical Reserve of the center, an area of 54 hectares located within the borders of the San Martin Regional Conservation Area "Cordillera Escalera". In this sector, in addition to a project of reforestation and conservation of the species of the Amazonian flora with a focus on medicinal plants, therapeutic activities are also performed such as the so-called traditional dietas, which offer participants a space of contact and reconnection with nature and with their inner self, to be able to work on certain psychological or emotional problems. For the future, the will of the center is to integrate the Botanical Reserve into an ecotourism route to be developed and managed in coordination with other local associations dedicated to biodiversity conservation.

The strategic importance of the Botanical Reserve can then be observed, serving both for therapeutic purposes, for the conservation of local endangered biodiversity, and for the promotion of sustainable development alternatives such as ecotourism, that at the same time take into account, protect and promote the cultural richness of the region derived from indigenous ancestral knowledge.
\end{abstract}

Keywords: medicinal plants, botanical reserve, traditional amazonian medicine, biodiversity conservation, therapeutic garden, mental health
Volume 3 Issue 2 - 2019

\author{
Fabio Friso, Matteo Politi \\ Center for the rehabilitation of drug addicts and research on \\ traditional medicines, Peru
}

Correspondence: Fabio Friso, Center for the rehabilitation of drug addicts and research on traditional medicines, Takiwasi, Prolongación Alerta 466, Tarapoto, Peru, Tel +39 3497189727, Email comunicaciones@takiwasi.com

Received: January II, 2019 | Published: March 06, 2019

\section{Introduction}

The Takiwasi Center for the rehabilitation of drug addicts and research on traditional medicines is a therapeutic community registered as NGO and located in the city of Tarapoto, in the Peruvian High-Amazon, where it was co-founded in 1992 by French physician Jacques Mabit. The innovative therapeutic proposal of the Center is based on the combination of conventional psychological and medical therapies and the knowledge and practices of traditional Amazonian medicine.

Takiwasi's overall mission is to contribute to improve the health conditions of the people and their environment and to work for the conservation of biodiversity by recovering, revaluing and preserving the human and natural resources linked to Amazonian traditional knowledge. The Amazon, environment where Takiwasi is located, is considered an endangered area in terms of biodiversity and cultural heritage, that needs therefore to be protected and preserved through sustainable activities. Since its early days, Takiwasi has worked for the recovery, preservation, research and promotion of natural medicine resources in cooperation with the indigenous people of the region. Traditional medicine summons not only botanical resources but also cultural heritage acquired over thousands of years which contribute to nature protection. This cultural heritage is also endangered by the rupture of the empirical transmission and its adulteration linked to the expansion of unsustainable activities in the Amazon Basin.

\section{Conservation and rescue of medicinal plants knowledge in indigenous communities}

Takiwasi develops numerous activities that directly aim at the preservation of Amazonian flora. Under a BioTrade approach, its Laboratory of Natural Products promotes the responsible use of medicinal plants as a strategy for the valorization and conservation of the biodiversity of the Amazonian ecosystems and the ancestral knowledge associated to its use. Takiwasi supervises the conservation of 2,910 hectares of forest in 3 native communities located in the San Martin region. Forest management plans are elaborated in a participatory way with the indigenous authorities, the producer organizations and the national forest conservation program of the Peruvian Ministry of the Environment. In this way, 74 agroforestry producers from 21 indigenous and farming communities in the Amazon Basin have been involved and more than 10,000 medicinal plants and trees have been planted in indigenous communities. Since 2006, more than 180 community health actors (medicinal plant experts, elders, midwives, etc.) have participated in knowledge collection workshops, created in order to rescue and register knowledge on medicinal plants in danger of being lost. To date over 250 plant-based recipes derived 
from traditional knowledge on medicinal and aromatic plants from the Amazon have been registered with the National Institute for the Defense of Free Competition and the Protection of Intellectual Property (INDECOPI). Through the training and transfer of technologies, Takiwasi engages indigenous women and men in a new economic activity based on the use and the generation of added value to the medicinal plants, contributing to the sustainable and inclusive development of the region and the conservation of the Amazon forest. This work has been acknowledged in a UNCTAD publication. ${ }^{1}$

\section{Case presentation}

\section{Botanical reserve in the regional conservation area "cordillera escalera"}

The Takiwasi Center directly manages a land of 54 hectares located within the borders of the Regional Conservation Area "Cordillera Escalera" at an average altitude of $600 \mathrm{~m}$ above sea level. The property is named by the institution "Reserva Botánica" (Botanical Reserve) and is administered jointly with the Regional Government of San Martin through a management plan approved by both parties. ${ }^{2}$ This land in the " 80 s lied in terrible conditions having been exploited for agricultural and livestock purposes for decades, thus provoking devastating effects on the local ecosystem. From the moment that this area has been bought by Takiwasi a process of conservation and reforestation began, by planting trees of native species to help the natural regeneration of the forest. This process is still ongoing. Within the main grounds of the Takiwasi Center, a Botanical Garden center has been set up with the purpose of producing seedlings of native plants, medicinal plants and others that are later transplanted into the Botanical Reserve.

The Regional Conservation Area "Cordillera Escalera" was created in $2005 .{ }^{3}$ It is a priority area for the conservation of mammals, amphibians, reptiles and birds. It presents within its limits a number of endangered species. Still, the area requires more studies to evaluate in details the species that live in it. ${ }^{3}$ Researches specifically on butterflies and moths living in the area are conducted by Urku Estudios Amazonicos, ${ }^{4}$ NGO who is one of Takiwasi's main allies. The main species living in the area are (listed with IUCN level of threat): Spectacled Bear (Tremarctos ornatus)-Vulnerable; Rio Mayo Titi (Callicebus oenanthe)-Critically Endangered; Jaguar (Panthera onca)-Near Threatened; Red Deer (Mazama americana); birds such as the Yellow Tucan (Aulacorhynchus huallagae) - Endangered; Green Macaw (Ara militaris) - Vulnerable; Andean Cock-of-therock (Rupicola peruviana); and amphibians such as the colored frog, among others. In the Cordillera Escalera lie as well several species of bromeliads, heliconias and orchids of different colors, sizes and shapes, that are associated with trees such as Pona (Dictyocaryum ptariense), Tornillo (Cedrelinga cateniformis), Shimbillo (Inga sp.), Cumala (Iryanthera sp.) and Renaco (Coussapoa sp.).

The area is threatened by locals and foreigners that intend to exploit its natural resources, as it lies relatively close to the city of Tarapoto. Deforestation causes include farmers, generally humble families who manage crops with very low productivity levels but with a strong environmental impact. The sustainable development policies implemented in recent years by the Regional Government and

${ }^{1} 20$ years of BioTrade: Connecting people, the planet and markets. United Nations Conference on trade and Development. http://unctad.org/en/ PublicationsLibrary/ditctedmisc2016d2 en.pdf

${ }^{2}$ Resolution n ${ }^{\circ} 221-2009-G R S M / P G R$

${ }^{3}$ Supreme decree $\mathrm{n}^{\circ} 045-2005-\mathrm{AG}$ international cooperation agencies have improved the economic status of part of the population, and the most common crops nowadays are cocoa and coffee. Despite this, in remote areas where there's lack of controls and monitoring by the state, there are still coca cultivations. One of the limits that are facing forest rangers in order to perform efficiently their monitoring activities are the threats they receive from unscrupulous mafias operating in the area, such as illegal loggers. The main threat to the local ecosystem is indeed represented by these individuals that want to commercialize the wood of the area using systems with a strong environmental impact that cause not only the destruction of the flora but also the disappearance of the fauna that experience a dramatic reduction of the habitat. Another source of concern is represented by major economic interests such as those of oil companies that aim at exploiting the oil reserves found underground.

\section{An inventory of the medicinal species transplanted in the botanical reserve}

The Medicinal Plants Botanical Garden of the Takiwasi Center counts with more than 80 medicinal plant species representative of local medical traditions. The outputs of this garden include: the supply of herbal medicines used in the treatment protocol of the Center, an ecological interface to introduce visitors to the fundamentals of traditional Amazonian medicine and biodiversity conservation, a nursery garden to produce a series of seedlings used within the reforestation programs performed in the Botanical Reserve. ${ }^{2}$

With the support of the Regional Government, in July 2018 Takiwasi performed an inventory of the medicinal plants currently growing in the Botanical Reserve that have been transplanted here throughout the last 20 years. Table 1 shows the results of this inventory.

Table I Inventory of the medicinal plants transplanted in the Botanical Reserve (in alphabetical order)

\begin{tabular}{lll}
\hline Plant & Scientific name & Quantity \\
\hline Ajo Sacha & Mansoa Alliacea & 2750 \\
Ayahuasca & Banisteriopsis caapi & 200 \\
Bobinsana & Calliandra angustifolia & 5 \\
Chacruna & Psychotria viridis & 2100 \\
Chiric sanango & Brunfelsia grandiflora & 500 \\
Coca & Erythroxylum coca & 20 \\
Copaiba & Copaifera officinalis & 25 \\
Estoraque & Styrax officinale & 25 \\
Jergon Sacha & Dracontium loretense & 30 \\
Paliperro & Tabebuia barbata & 10 \\
Papelillo & Cariniana decandra & 8 \\
Sangre de grado & Croton lechleri & 35 \\
Uchusanango & Tabernaemontana sananho & 250 \\
Ushpawasha sanango & Tabernaemontana undulate & 80 \\
\hline
\end{tabular}

\section{Botanical reserve as wild therapeutic garden}

The Botanical Reserve has basic infrastructure for receiving patients and researchers, and represents the environment where one of the main therapeutic activities proposed by the Takiwasi Center treatment protocol takes place, the so-called dieta (diet). The dieta 
is one of the main practices of traditional Amazonian medicine. ${ }^{5}$ It consists of a retreat in isolation with the ritualized intake of local medicinal plants known as "teacher plants" considered capable of transmitting knowledge and healing to the person who drink them. The intake is accompanied by some strict rules that have to do with isolation, dietary restrictions, physical and psychological norms, sexual abstinence, among others. Takiwasi uses approximately 20 different plant species for this purpose, the majority of which are poorly described in the scientific literature. ${ }^{7}$ This practice allows patients to address psychological and emotional traumas, create a special contact with nature and the inner self, dedicate to a holistic depuration that eliminates toxic elements at physical, emotional, mental, and spiritual levels, while allowing at the same time to reconnect with repressed emotions, cleanse the body and connect with the sacred dimension of nature.

Cultivating healthy relationships between humans and the environment is fundamental to many indigenous societies, including the Amazonian one. The traditional therapeutic tool of the dieta is becoming more and more popular within the global audience and users from all over the world are traveling to the Amazon to undertake this kind of treatment. Since 1996, Takiwasi reports having welcomed more than 2,300 people from around the world who have come specifically to experience the dieta. This tool from the Amazonian medical tradition is nowadays increasingly spreading towards Western cultures and contexts. ${ }^{8}$

Ecopsychology reports affirm that access to nature acts as a protective resource to maintain psychological well-being. ${ }^{9}$ The healing powers of human interaction with plants is recognized and encouraged also by institutions such as the National Garden Bureau. ${ }^{4}$ In the case of the Amazonian dieta, the immersion of the patient into the exuberant nature of the jungle, with very few belongings and a total separation from electronic devices, turns into a fundamental element of healing. Together with this experience of extreme austerity and introspection comes a great feeling of recognition and gratitude that often takes a spiritual form. During a dieta, people find themselves spending a lot of time in silence; greater space is given to most intuitive-instinctual sphere of the brain, usually repressed in the daily life of the average Westerner. The observation and encounter with animals, from the littlest insect, to the birds, frogs or monkeys, can further contribute to the feeling of "reconnecting with nature," that has been commonly reported by participants with urban backgrounds. ${ }^{8}$

We can observe that the Botanical Reserve of Takiwasi offers to the visitor several of the eight main characters that make up parks and gardens, ${ }^{10}$ as for example: peace, silence and care; fascination with wild nature; a variety of species of animals and plants; a room offering a restful feeling of "entering another world", a coherent whole. These characters communicate directly with the visitor and appeal especially to the most vulnerable persons, those who strive to find balance with themselves, which indeed correspond to the profile of person welcomed by the Takiwasi Center.

Other therapeutic activities that have to do with the interaction between the human being and nature take place in the main facilities of the Takiwasi Center, where drug-addict patients take part in daily occupational ergotherapy activities along their nine months residential rehabilitation program. These activities include gardening and the care of the Botanical Garden, in addition to the planting and care of a medicinal plant with which they are identified. The planting is carried out as part of the so-called "commitment ritual" in which the patients commit in front of what they consider most sacred to get to the end of

${ }^{4}$ https://ngb.org/grant-application/ their treatment as well as to make a radical (positive) change in their life once they have been discharged from the Takiwasi Center.

\section{Perspectives on ecotourism}

As a parallel strategy to link conservation with environmental education on the medicinal plants and flora of the region, the Takiwasi Center is promoting the creation of an eco-touristic route that involves not only the Medicinal Botanical Garden, ${ }^{2}$ but also the Botanical Reserve. Takiwasi's initiative wants to develop sustainable tourism that is respectful of the environment and can create awareness among visitors and local people on the subject of conservation. Since mid2017 the Center is part of an alliance ${ }^{5}$ formed by local associations and NGO that have, among other purposes, the common primary goal of the sustainable use of the touristic resources of the area.

Every year, Takiwasi is receiving visitors interested in the use and knowledge of traditional medicine and that want to participate in an instance of self-observation such as the dieta. These people visit the Botanical Reserve and get to know the conservation project. By creating a modern interpretation center and improving the conditions of the facilities, trails and signs of the Botanical Reserve, the objective is to be able of welcoming people interested in an outdoor experience that could enjoy the touristic resources of the area. Valuable information about the local biodiversity and about ways to engage in ecotourism activities that have low environmental impact will be offered to the visitors so that their green culture will be benefited.

\section{Discussion}

The efforts made by the Takiwasi Center for the recovery, preservation, research and promotion of natural resources related to the local traditional medicinal knowledge are clearly expressed in the Botanical Reserve that, together with the previously analyzed Botanical Garden ${ }^{2}$ proves to be a successful example of integration between biodiversity conservation, sustainable development and therapeutic practices, in relation with the general frame of Planetary Health promotion. The strategic importance of the Botanical Reserve can then be observed in its multidisciplinary use, since it both serves for therapeutic purposes, for the conservation of local biodiversity, for the dissemination of environmental consciousness, for the promotion of sustainable economic development activities, and, most importantly, for the protection and promotion of the cultural richness of the region linked to indigenous ancestral knowledge, that is being recovered for the benefit of local and international people, who are looking more and more for therapeutic spaces that can help human beings reconnect with nature and take care of the ecosystems.

\section{Acknowledgments}

None.

\section{Conflicts of interest}

The authors declare that there is no conflicts of interest.

\section{References}

1. Giove R. La liana de los muertos al rescate de la vida, medicina tradicional amazónica en el tratamiento de las toxicomanías, Tarapoto, Takiwasi, Perú; 2002

2. Politi M, Friso F. Amazonian medicinal plants botanical garden of Takiwasi Center in Peru; a case report of 25 years' hands-on experience. Horticulture International Journal. 2018;2(3):69-71.

${ }^{5}$ Federation of the Ecological Associations of the Cordillera Escalera - Lung of the World. 
3. Gobierno regional san martin, plan maestro 2015-2020 del área de conservación regional cordillera escalera (ACR-CE); 2015.

4. Vecco C, Gonzales R. Lepidoptera en San Martín. Introducción a la diversidad y ecología de mariposas y polillas amazónicas. 2006;96.

5. Luna LE. Vegetalismo: shamanism among the mestizo population of the peruvian Amazon, in Department of comparative religion. University of Stockholm: Stockholm, Sweden. 1986;202.

6. Jauregui X, Clavo ZM, Jovel EM, et al. Plantas con madre: Plants that teach and guide in the shamanic initiation process in the East-Central Peruvian Amazon. Journal of Ethnopharmacology. 2011;134(3):739752.
7. Politi M, Friso F, Mabit J. Plant based assisted therapy for the treatment of substance use disorders - part 1 . The case of Takiwasi Center and other similar experiences. Revista Cultura y Droga. 2018;23(26):99-126.

8. https://chacruna.net/healing-knowledge-amazonian-shamanic-diet/

9. Brito G, Sieber C. Plant teachers as a source of healing in the peruvian amazon. In Wild Foresters: practicing nature's wisdom, DT Alan RD, editor. New Society Publishers. 2008;288:9.

10. Stigsdotter UA, Grahn P. What makes a garden a healing garden?. Journal of Therapeutic Horticulture. 2002;13:60-69. 